\title{
Aerial-hawking bats adjust their use of space to the lunar cycle
}

\author{
Manuel Roeleke ${ }^{1,2^{*}}$ D , Tobias Teige ${ }^{3}$, Uwe Hoffmeister ${ }^{4}$, Friederike Klingler ${ }^{1}$ and Christian C. Voigt ${ }^{1,2}$
}

\begin{abstract}
Background: Animals change their habitat use in response to spatio-temporal fluctuation of resources. Some resources may vary periodically according to the moonphase. Yet it is poorly documented how animals, particularly nocturnal mammals, adjust their use of space in response to the moonphase.

Here, we asked if an obligate nocturnal mammal, the aerial-hawking common noctule bat (Nyctalus noctula), adjusts its 3-dimensional flight behaviour and habitat use to the lunar period. Using miniaturized GPS loggers, we recorded 3-dimensional flight tracks of N. noctula and related these to a canopy height model derived from aerial laser scans to investigate whether bats adjust forest strata use to moonlight intensities.

Results: Noctules frequently foraged above the canopy of coniferous forest at low moonlight intensities, but switched to using open grasslands and arable fields in nights with high moonlight intensities. During the few occasions when noctules used the forest during moonlit nights, they mostly restricted their use of space to flying below the canopy level. The median overall flight altitude of $N$. noctula equalled $13 \pm 16 \mathrm{~m}$ but reached up to $71 \mathrm{~m}$ above ground ( $97.5 \%$ quantile).

Conclusions: Our findings argue against general lunar phobic behaviour of aerial-hawking bats. We suggest that the preferred use of open fields around full moon may be a strategy of noctules to increase the success of hunting airborne insects at night. Specifically, the adjustment in use of space may allow bats to hunt for insects that emerge and disperse over open fields during bright moonlight.
\end{abstract}

Keywords: Flight altitude, Forest structure, Habitat use, LiDAR, Moonlight, Nyctalus noctula

\section{Background}

Animals live in heterogeneous landscapes that offer resources for different requirements, such as breeding, shelter, or foraging [1]. Such functional heterogeneity within landscapes may occur in space and time alike [2]. At the spatial scale, animals will perceive the temporal heterogeneity of resource availability as a change in habitat suitability (cf [3]), which may result in distinct temporal patterns of use of space. Temporal changes in habitat suitability may be partially or completely unpredictable, e.g. when they are driven by local weather conditions [4], or distinct events like human hunting activities [5] or extreme weather conditions [6]. However, temporal changes in habitat suitability may also occur periodically.

\footnotetext{
* Correspondence: roeleke@izw-berlin.de

${ }^{1}$ Leibniz Institute for Zoo and Wildlife Research, Alfred-Kowalke-Str. 17, 10315 Berlin, Germany

${ }^{2}$ Institut für Biologie, Freie Universität Berlin, Takustr. 6, 14195 Berlin, Germany Full list of author information is available at the end of the article
}

Periodic changes in habitat suitability and resulting changes in habitat use happen on very different timescales, ranging from hourly (e.g. tidal flooding [7]) to daily (e.g. day-night changes or periodic human disturbances [8]) and seasonal patterns (e.g. snow cover [9]). According to the optimal foraging theory [10], animals should react towards periodic and thus predictable temporal heterogeneity in habitat suitability with a concordant adjustment of their use of space.

The moon phase presents a highly predictable periodic change in the environment to which various animals respond. Many studies reported so-called lunar phobia in prey species, a term describing the negative response of animals towards bright moonlight by either decreasing overall activity $[11,12]$ or by adjusting habitat use and behaviour to prevent encountering visually oriented predators [11, 13-16]. Predators on the other hand may increase their activity during low or intermediate moonlight levels to enhance foraging success [17-19]. This 
may result in complex temporal and spatial patterns of predator-prey interactions [20]. Yet, some mammals are predator and prey at the same time, a fact that may result in a trade-off between increasing foraging activity when prey is easy to perceive, and decreasing activity at the same time in order to avoid becoming prey themselves during moonlit nights [21]. The optimal strategy thus depends on trading the energetic benefit from increased capture rate when hunting prey which is sensitive to the moonphase against the potential costs of increased predation risk in bright moonlight. One such strategy can be adjustment in use of space according to the anticipated resource distribution and likelihood of predation [21,22].

Although bats are commonly perceived as lunar phobic animals [23], the picture within the order of bats is complex [24]. Thus far, lunar phobia has been described exclusively in some tropical bat species [25-27], yet with different reasoning for the underlying causes, such as predator avoidance or decreased prey detectability. On the other hand, studies on temperate zone bats could not show effects of moonlight on foraging activity [28-31]. However, although temperate zone bats might not decrease their overall flight activity, they may still adjust their vertical use of space, probably to increase foraging success [32]. This suggests that predation risk is only a minor driving force for temperate zone bats to alter their behaviour ( $\mathrm{cf}$ [33]) and can be outweighed by the potentially higher foraging success during moonlit nights. Indeed, temperate zone bats face relatively small numbers of airborne predators during the night, and most aerial predators hunt only opportunistically upon bats when bats emerge from roosts at dusk [34-36]. Especially fast-flying bats that are adapted to forage in the open space [37] might be able to easily escape nocturnal birds of prey such as owls. This is probably also the reason why fast-flying species, like e.g. Pipistrellus nathusii or Nyctalus noctula, are the most light tolerant bats of the temperate zone (reviewed in [38]). Open-space foraging insectivorous bats of the temperate zone may thus be perceived as top predators. This will result in a high selection pressure to increase foraging efficiency, but a minor pressure to avoid predators. Bats might thus be highly flexible in their use of habitats and altitudes, enabling them to feed opportunistically on patches of prey aggregations, such as swarming insects. Indeed, many insects that hatch synchronously adjust their emergence to the lunar cycle [39, 40]. Some studies suggest a decrease of aquatic insects near full moon [41], whereas activity of terrestrial crop pests may increase with moonlight intensity [42]. These studies show that the timing of emergence is not consistent for all insect species, meaning that abundances of some insect prey species like specific moths may be low $[40,43]$ while the abundance of other insect prey species, e.g. Trichoptera or Diptera, may be high during the full moon $[42,44,45]$.
Such species-specific responses towards the lunar cycle suggest temporal fluctuation of prey availability that is specific for the habitats that an affected prey species uses.

Here, we evaluate how the 3-dimensional use of space of common noctules (Nyctalus noctula) changes with moonlight intensity. Nyctalus noctula is a fast-flying species that forages in the open aerosphere [46], and is known for its flexibility in exploiting temporarily occurring and patchily distributed insect swarms (e.g. $[47,48])$. Accordingly, if habitat specific insect abundances differ between moon phases, noctules should adjust their use of space to increase foraging efficiency. To test this hypothesis, we tracked common noctules with GPS loggers and related their habitat use and the use of forest strata derived from airborne laser scans (LiDAR) to the moon phase.

\section{Methods}

\section{Study site and GPS tracking}

In July 2015 and 2016, we equipped nine Nyctalus noctula (five post-lactating females and four males) with GPS loggers (Robin Cell Guide, Lucidlogix Technologies Ltd., Kfar Netter, Israel) to record 3-dimensional positions of flying bats. The study area in North-Eastern Germany consisted mostly of loose pine forest plantations interspersed by forest tracks (51\%), but also included open fields (21\%), several larger water bodies (14\%), mixed or deciduous forest (8\%), and small villages (5\%) (Additional file 1). All tagged individuals roosted in artificial roost boxes in a pine stand, located about $50 \mathrm{~km}$ south of Berlin, Germany. During morning hours, we removed bats temporarily from their roosts and glued a GPS logger onto the dorsal fur of each bat using latex based surgical glue (Manfred Sauer, Lobbach, Germany). GPS loggers were placed into rubber balloons for protection against humidity. The whole unit weighed in total about $3.4 \mathrm{~g}$, which corresponded to 10 to $13 \%$ of the bats' body masses. Within a maximum of ten days after deployment of the GPS units, we relocated the tagged bats by using radio telemetry, recaptured them from their artificial roosting boxes or treeholes, and removed the GPS units. Similar to other studies $[49,50]$, we did not notice any adverse effects of the relatively large weight of GPS units on the bats. All procedures were approved by the animal welfare and ethics committee of the Landesamt für Umwelt, Gesundheit und Verbraucherschutz Brandenburg (permit: 2347-16-2015) and by the federal agency for nature conservation (permit: LUGV_N1-4743/103 + 5\#283569/2015). All institutional and national guidelines for the care and use of animals were followed.

\section{Data acquisition and processing}

We programmed the GPS loggers to record GPS locations every $15 \mathrm{~s}$ from sunset to sunrise until batteries 
expired. In total, we recorded about 7000 GPS locations from nine bats from which we retrieved GPS units. All bats started foraging trips around sunset, but only six bats performed additional trips within one night after times of inactivity. In these cases we divided the GPS locations of each bat into several continuous trips with regular GPS fix intervals, and deleted occasional GPS fixes when bats were not moving but remained in or close to their roosts. Further, we excluded flight times when - according to the three closest weather stations more than $50 \%$ of the sky was covered by clouds, resulting in 22 flight trips (Table 1 and Additional file 2, 4929 GPS locations, between one and five trips or one and three nights per bat). Since altitude estimates of GPS loggers do not have the same accuracy as locations in the 2-dimensional plane, about $16 \%$ of locations yielded false negative flight altitudes at $-4.3 \mathrm{~m}$ (median) below ground. Most of these localisations were recorded when bats started their flight trips, flew within the forest, or when bats hunted above water bodies (see points with altitude zero in Additional file 1). Since the majority of these measures were thus recorded in situations when low flight altitudes are most plausible, we decided to off-set these points to zero and still include them in the analysis. We think that excluding these points from the analysis may have led to a severe overestimation of flight altitudes. However, one must be aware that the offsetting of false altitude measures leads to an underestimation of flight altitudes of localisations that are close to the ground or close to the canopy. Altitude measures of localisations further away from the ground or habitat structures on the other hand are measured at higher accuracy since satellite detection is not hampered at higher altitudes.

\section{Habitat use and movement behaviour}

We assigned underlying land use types to the respective GPS locations using habitat maps derived from aerial infrared imagery [51] grouped into six categories: coniferous forest (i.e. mainly pine plantations), deciduous and mixed forest, open fields (incl. arable land, meadows,

Table 1 Nights during which we tracked individual bats

\begin{tabular}{lll}
\hline Animal ID & Dates & No. of trips \\
\hline A132503 & 02. July 2015 & 3 \\
A132504 & 02. July 2015 & 1 \\
A132518 & 02-03. July 2015 & 3 \\
A132536 & 06. July 2015 & 2 \\
A132726 & 11. July 2015 & 1 \\
A132722 & 11. July 2015 & 1 \\
A132542 & 16-18. July 2015 & 5 \\
A132704 & 16-17. July 2015 & 5 \\
A132670 & 28. July 2016 & 1 \\
\hline
\end{tabular}

and grassland), urban areas, scrub or areas with successional growth, and water bodies or swamps. To evaluate the use of forest strata, we further assigned tree heights to the respective GPS locations when bats flew above the forest canopy. For this, we used aerial laser scan (LiDAR) data with a mean resolution of 2.9 points $/ \mathrm{m}^{2}$ and an accuracy of $<20 \mathrm{~cm}$, collected in 2009 by the federal office of the state of Brandenburg (https://www.geobasis-bb.de/ geodaten/dgm-laserscanrohdaten.htm). Based on these raw data, we calculated a canopy height model (chm) for the forest areas, using the free version of the software LASTools (rapidlasso $\mathrm{GmbH}$, Gilching, Germany) and following the tutorial by Isenburg [52]. A detailed description of the processing of the LiDAR data from raw 3-dimensional coordinates to the chm model is included in the supplement (Additional file 3). To assign the height of the uppermost canopy layer to the respective GPS points on a meaningful scale, we calculated the $95 \%$ quantile of the canopy height values within a radius of $20 \mathrm{~m}$ from the GPS location. For each GPS location, we specified the moonlight intensity as either low ( 0 to $20 \%$ of moon visible) or high ( 80 to $100 \%$ of moon visible). If the bats performed foraging trips before moonrise, we defined the according moonlight intensity as low. This resulted in flight tracks for four bats during high moonlight intensity in early July 2015 (one female and three males), and tracks from seven bats during low moonlight intensity in early and mid July 2015 and late July 2016 (4 females and 3 males) [Additional file 2].

We used the function fitHMM from the $\mathrm{R}$ package moveHMM [53] to assign two different movement behaviours (i.e. foraging with short step length and large turning angles, or commuting with larger step length and smaller turning angles) to single GPS fixes. Whenever the probability of correct classification was below $75 \%$, we categorized the movement of a bat as undefined.

\section{Statistics}

We used Mann-Whitney-U-tests to compare the flight altitudes of $N$. noctula between nights with high and low moonlight intensities above different habitats. To evaluate preferences for certain habitat types, we applied an use-versus-availability approach [54]. We defined available habitat for the respective tracks by five randomly rotated GPS tracks per recorded track (function NMs.randomShiftRotation, [55]) to keep the properties, such as the spatial autocorrelation structure, of the movement tracks [56]. The centre of rotation was set to the starting point of the respective track. We then fitted a binomial generalized mixed model with the interaction of habitat class and moonlight intensity as fixed factors to explain the identity of locations (i.e. real bat or randomly rotated track). We used the respective trips nested within the individual bat as a random factor to account for dependency of locations within single trips and between different trips of the same 
individual. We further included the sex of the tracked individuals as a random factor to account for potential biases in the dataset. We also modelled the probability of bats flying above or below the forest canopy, using a similar mixed model with only moonlight intensity as a fixed factor. Full models were compared to reduced models using Aikaike Information Criteria corrected for small sample sizes. We calculated $95 \%$ confidence intervals and plotted the fixed effects using the $R$ package effects [57]. We assume statistical significant preference / avoidance when $95 \%$ confidence intervals did not overlap with a probability value of 0.5 . For statistical tests, we assumed a significance level of 0.05 . Unless stated otherwise, all measurements are given as median \pm median absolute deviation (mad). Throughout the text, ranges are given as 2.5 to $97.5 \%$ quantiles. Data processing and statistics were done with the software $R$ (Version 3.3.2). GPS data are stored at the movebank data repository (Study ID 297041945 at https:\|movebank.org).

\section{Results}

\section{Moonlight and flight altitude}

The median overall flight altitude of $N$. noctula equalled $13 \pm 16 \mathrm{~m}$ (median \pm median absolute deviation), but reached up to $71 \mathrm{~m}$ above the ground (97.5\% quantile). This corresponded to a maximum altitude of $63 \mathrm{~m}$ above the canopy level $(97.5 \%$ quantile) when noctules flew above forested areas In general, $N$. noctula flew at lower altitudes during high than during low moonlight intensities, except when flying above urban areas (Fig. 1, Table 1). N. noctula used forested areas less often during high than during low moonlight intensities (Table 2). When the bats used the forested areas during high moonlight intensities nonetheless, they flew mostly underneath the canopy level (Fig. 2).

\section{Moonlight and habitat use}

Irrespective of the moonlight intensity, $N$. noctula consistently preferred water bodies (Fig. 3). The recorded movement behaviour suggests that bats used the water bodies mainly for foraging (Fig. 4, in total $67 \%$ of the GPS locations over water were classified as foraging). At high moonlight intensities, noctules flew more often above open fields than at low moonlight intensities (Fig. 3). Their movement behaviour above open fields also suggests increased foraging activity under moonlit conditions (Fig. 4, $36 \%$ of GPS locations defined as foraging during low moonlight intensities, but 70\% of GPS locations defined as foraging during high moonlight intensities).

$N$. noctula showed relative avoidance of coniferous forest at high moonlight intensities. Our model yielded also different significant effects of moonlight intensity on the use of urban areas, deciduous forest, and scrub or areas with successional growth (Fig. 3), as well as a

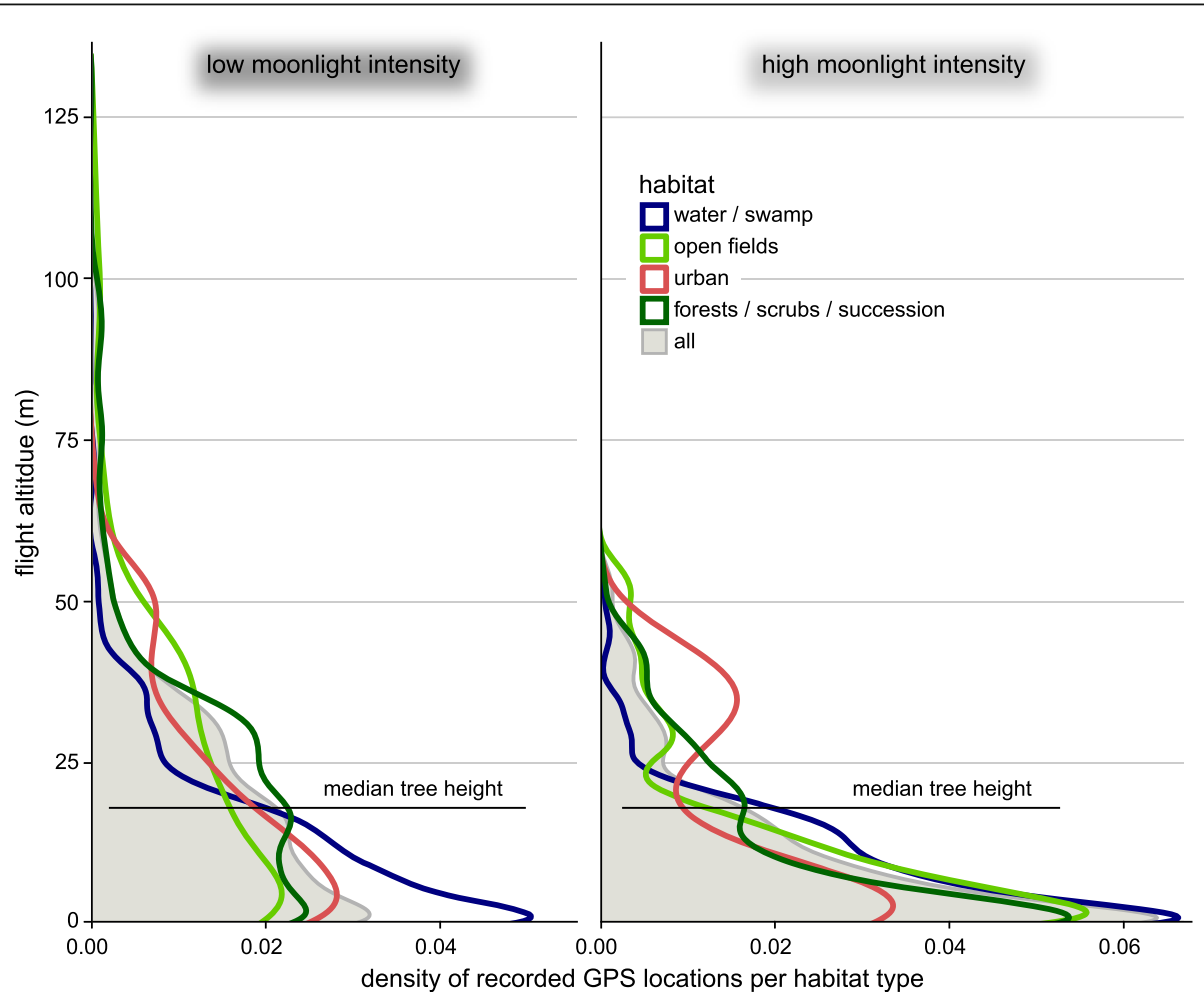

Fig. 1 Probability of N. noctula flying above the canopy level when using forested areas, depending on the moonlight intensity. Dots depict effect estimates from the underlying model, bars depict the corresponding 95\% confidence intervals 
Table 2 Flight altitude and relative time spend in different habitats during different moonlight intensities

\begin{tabular}{|c|c|c|c|c|c|}
\hline & \multicolumn{2}{|l|}{ High moonlight intensity } & \multicolumn{2}{|l|}{ Low moonlight intensity } & \multirow[b]{2}{*}{$\begin{array}{l}\text { Sig. diff. of flight } \\
\text { altitudes }\end{array}$} \\
\hline & $\begin{array}{l}\text { Flight altitude (median } \pm \\
\text { mad) }\end{array}$ & $\begin{array}{l}\text { Time spend in } \\
\text { habitat }\end{array}$ & $\begin{array}{l}\text { Flight altitude (median } \pm \\
\text { mad) }\end{array}$ & $\begin{array}{l}\text { Time spend in } \\
\text { habitat }\end{array}$ & \\
\hline Water / swamps & $6 \pm 8 m$ & $36 \%$ & $8 \pm 12 m$ & $24 \%$ & yes, $p<0.001$ \\
\hline Open fields & $6 \pm 10 m$ & $29 \%$ & $18 \pm 23 \mathrm{~m}$ & $9 \%$ & yes, $p<0.001$ \\
\hline $\begin{array}{l}\text { Forest / scrub / } \\
\text { succession }\end{array}$ & $6 \pm 9 m$ & $31 \%$ & $18 \pm 17 \mathrm{~m}$ & $62 \%$ & yes, $p<0.001$ \\
\hline Urban & $7 \pm 11 \mathrm{~m}$ & $4 \%$ & $13 \pm 17 \mathrm{~m}$ & $5 \%$ & no, $p=0.25$ \\
\hline All & $6 \pm 9 \mathrm{~m}$ & $100 \%$ & $15 \pm 17 \mathrm{~m}$ & $100 \%$ & yes, $p<0.001$ \\
\hline
\end{tabular}

significant decrease of movement behaviour associated with foraging activity in deciduous forest during high moonlight intensities (Fig. 4). However, these habitat types accounted only for a small fraction within the landscape, and since the GPS locations recorded in these habitat types only sum up to $12 \%$ of the total number of locations, we refrain from further interpretation of these results.

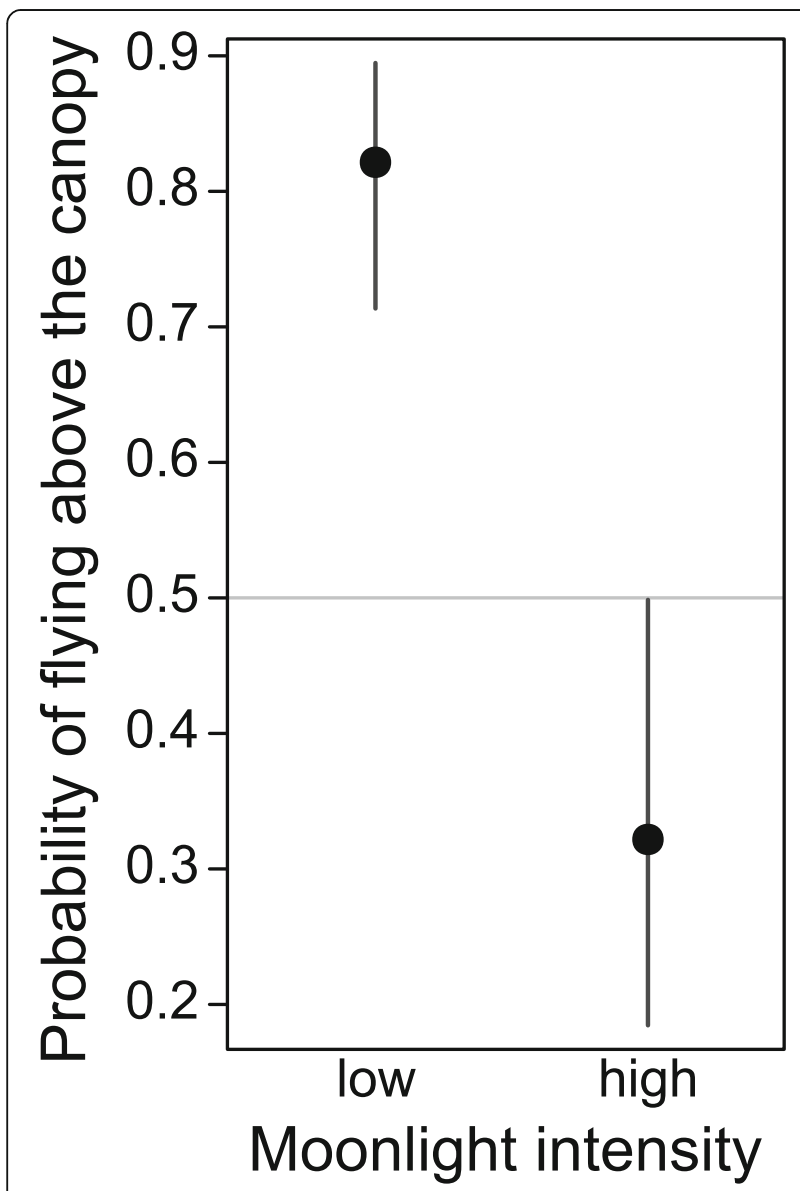

Fig. 2 Relative distribution of flight altitudes of $N$. noctula for different habitat types and for all recordings, recorded at different moonlight intensities. The horizontal black line shows the median tree height, derived from all bat locations in forested areas

\section{Discussion}

In early summer, we tracked nine common noctule bats (Nyctalus noctula) each for a period of several days in an area that was dominated by pine silviculture. Irrespective of the moonlight intensity, bats preferred water bodies for foraging, but also spent a considerable amount of time within or above the forest. However, during high moonlight intensities, bats used the forest less often but shifted their foraging activity towards open fields. When still using the forest during high moonlight intensities, bats tended to then fly under the shelter of the canopy level. $N$. noctula flew closer to the ground during high than during low moonlight intensities. It is intrinsic to the study setup that tracking during full moon and new moon cannot occur at the same time. However, we tracked all noctules (except one recorded in 2016) within two weeks in July 2015, a period of the year with constantly high insect abundance [58] and diversity [59], and without substantial changes in the annual life cycle of noctules [60, 61]. Further, there were no significant differences between ambient temperatures during the flights recorded at different moon phases (high moonlight intensity: $20.6 \pm 3.6{ }^{\circ} \mathrm{C}$, low moonlight intensity: $19.6 \pm 4.0{ }^{\circ} \mathrm{C}$, mean \pm standard deviation) which might have influenced insect abundances. We are thus confident that the observed space use patterns are indeed related to moonlight intensities, and not confounded by the different days during which we tracked bats.

\section{Habitat use and the effect of moonlight}

Waterbodies were the most preferred habitats for flight and foraging activity, followed by deciduous forests, and scrubland or successional areas. This is in accordance with a study by [62] which combined bat activity based on ultrasonic recordings with LiDAR data of forested area. In that study, long-range echolocating bats, such as $N$. noctula, were most active over rather heterogeneous areas, i.e. forest gaps and successional patches. However, since deciduous forests and successional areas were rare in our study area, the observed patterns for these habitats have to be interpreted with caution.

When noctules were foraging over waterbodies, they were least influenced by moonlight intensity. This is in 


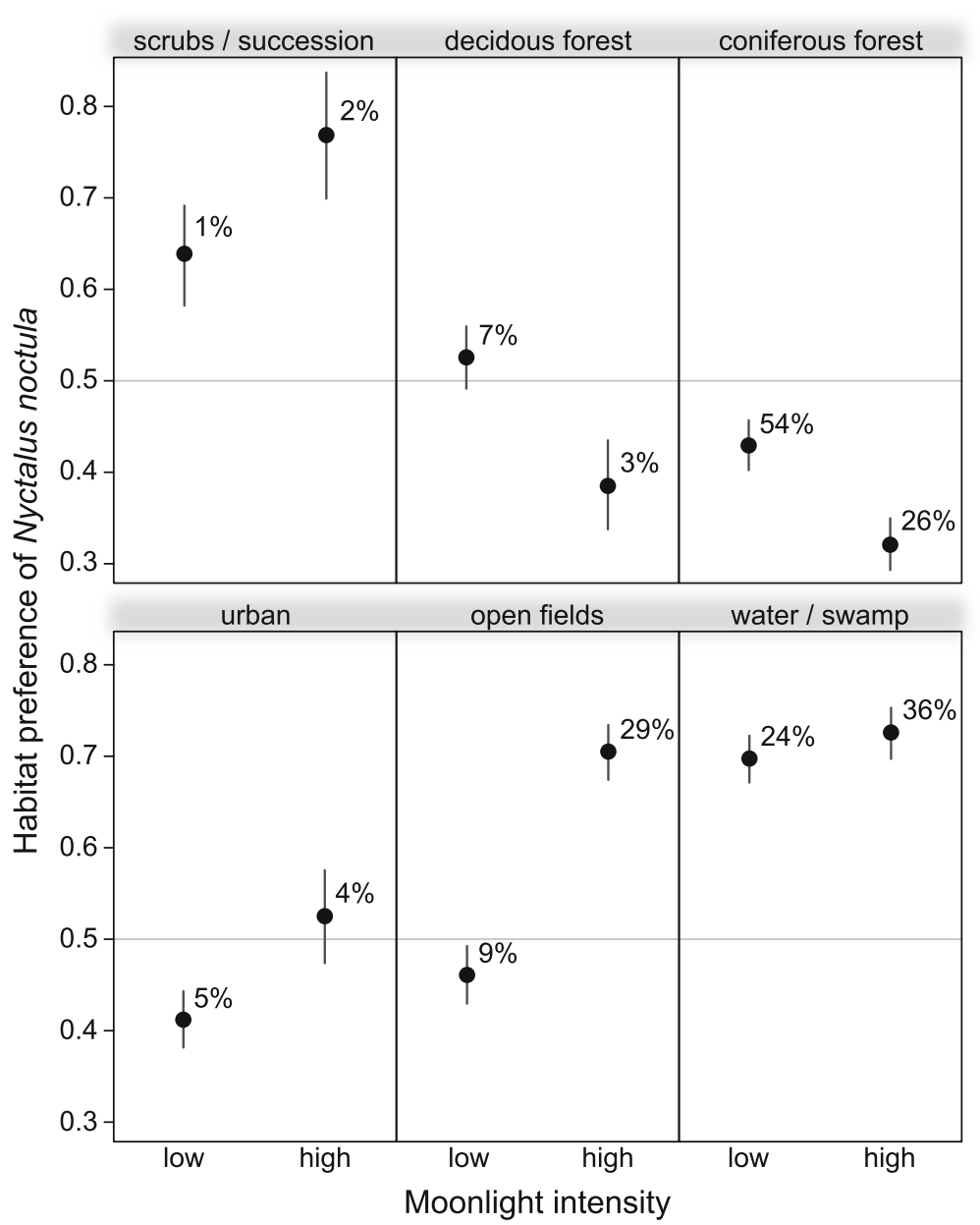

Fig. 3 Preference of $N$. noctula for different habitat classes, depending on the moonlight intensity. Values above 0.5 indicate that $N$. noctula used this habitat more frequently than expected from availability derived from randomly rotated tracks. Values smaller than 0.5 indicate relative avoidance of the respective habitat type. Dots depict effect estimates from the underlying model, bars depict the corresponding $95 \%$ confidence intervals. Percentages depict the relative number of GPS locations within each habitat type for the respective moonlight intensity

concordance with former studies on habitat use of $N$. noctula [50,63] and several dietary studies showing that $N$. noctula regularly feeds on aquatic insects [47, 64]. Insects hatching from the water surface are probably the most predictable food source for noctules in midsummer, irrespective of moonlight intensities. However, N. noctula is also known for its high dietary flexibility (reviewed by [48]), which explains the use of all available habitats within our study area.

We further found that the flight space above or within coniferous forests was overall used less often than expected from availability. The avoidance of coniferous forests was most pronounced during high moonlight intensities. When $N$. noctula nonetheless used the coniferous forest during high moonlight intensities, most GPS positions were recorded underneath the canopy level, and not above, as was the case when moonlight intensities were low. This is surprising since $N$. noctula is adapted to fly in uncluttered space at high forest strata [37, 65]. The flights underneath the canopy layer during both high and low moonlight intensities were probably mainly associated with roost searching and not foraging behaviour. A possible explanation for the lack of flights above the canopy during high moonlight intensities could be that foraging above the canopy at high moonlight intensities may not be beneficial enough for $N$. noctula to compensate for increased predation pressure from occasional bat-hunting birds of prey which are associated with the edge space between forests and open fields [66]. Alternatively, the lack of observations of noctules hunting above the forest canopy at high moonlight intensities might also simply be explained by the shift towards more profitable hunting areas, i.e. open fields.

However, one should be aware that altitude measures of bats that fly close to and especially underneath the canopy are suffering from reduced accuracy. Satellite 


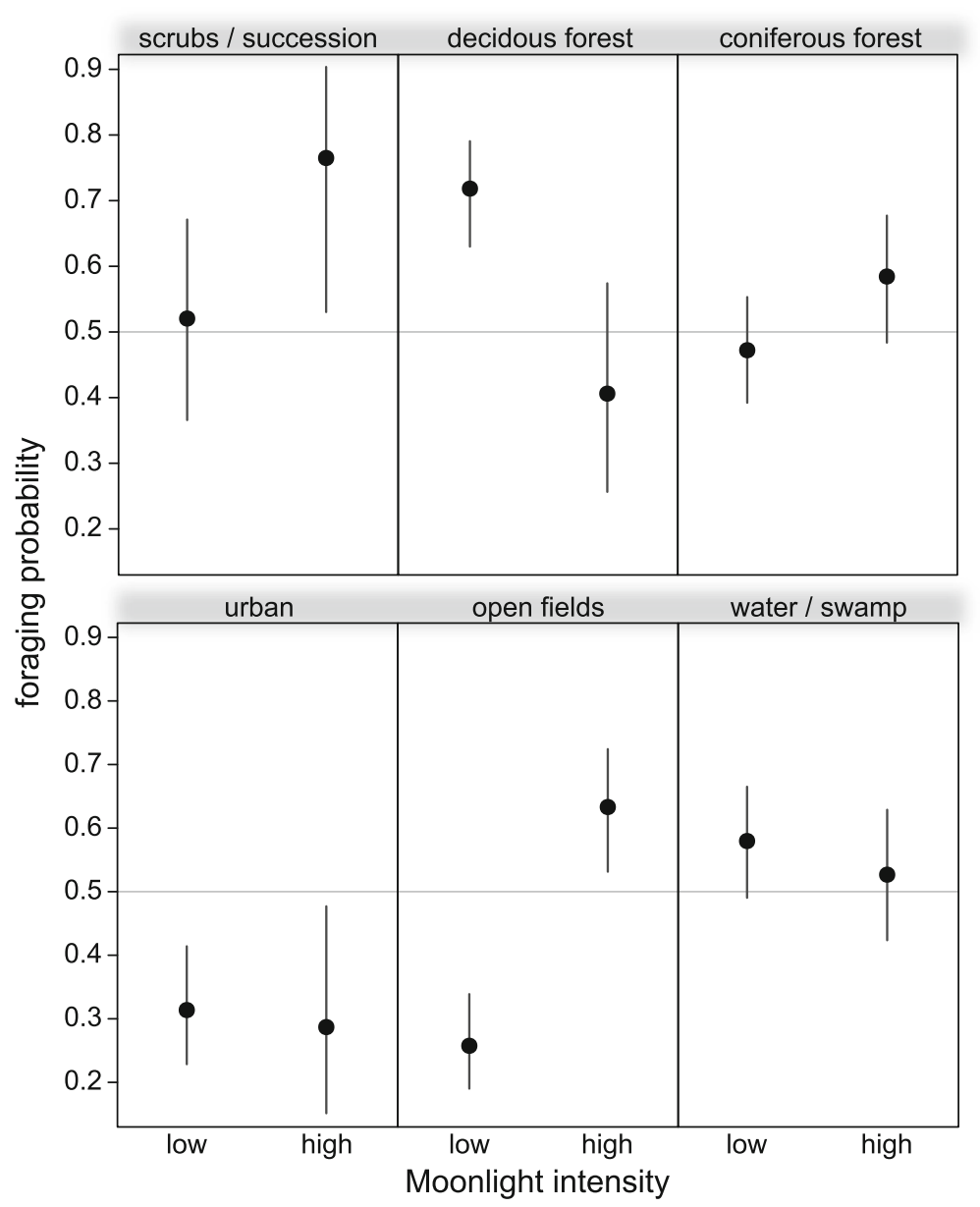

Fig. 4 Probability that N. noctula showed movement behaviour associated with foraging, shown for the different habitat types and depending on the moonlight intensity. Values higher than 0.5 indicate that $N$. noctula used the respective habitat primarily for foraging during the given moonlight intensity. Dots depict effect estimates from the underlying model, bars depict the corresponding 95\% confidence intervals

signals blocked or reflected by vegetation or other structures and surfaces arrive with a delay and thus are more likely to result in falsely negative altitude estimates. Yet, the obvious breakpoint around the median canopy level height in the distribution of flight altitudes above forested areas makes us confident that the overall pattern of flight altitudes in relation to the canopy reflects the true behaviour of $N$. noctula.

Concurrent with decreased use of forest, activity of noctules above open fields and adjacent urban areas was highest during flight trips at high moonlight intensities. This finding is contradictory to the often proposed lunar phobic behaviour of bats (reviewed by [24]) associated with predator avoidance.

Indeed, some authors suggest that responses of bats towards the moon phase may most likely be driven by prey availability (e.g. [25]). Hecker and Brigham [32] found that under moonlit conditions, some bat species (mainly belonging to the genus Myotis) shifted their hunting grounds from lower strata of the forest to the canopy level. They conclude that prey availability rather than predator avoidance may be the driving factor. This is supported by Speakman et al. [67], who found that bats continued their night activity patterns in the Nordic summer, despite bright conditions during the whole night and despite higher prey availability at daytime. They conclude that night activity of bats in temperate zones may have evolved to avoid competition with birds, but not to reduce predation pressure. This is supported by Voigt and Lewanzik [68] who suggest that during daytime, flight costs for bats are considerably higher than for birds, and another study by Speakman and Webb [69] showing that Nyctalus azoreum primarily forages at night time, although avian predators are not present in its habitat. Indeed, dietary studies on night active birds of prey such as owls indicate that bats comprise only a minor fraction of their prey [34-36], but this might vary geographically [70] and seasonally [71]. Despite the low fraction of bats in the diet of predators, Speakman [72] estimated that birds of prey may still account for $10 \%$ of the mortality of bats in 
Britain. Based on that estimate, one would assume that also temperate bats are under strong selection pressure to avoid predators. Our results on the effect of moonlight on the activity of $N$. noctula appear inconsistent with lunar phobia being caused by predator avoidance. The tracked bats exhibited a behaviour which is better explained by the term lunar philia, since they shifted their use of space towards open fields under moonlit conditions. In this context, lunar philia has to be understood as an active habitat choice towards landscapes where bats are exposed to moonlight under bright conditions, without any a priori implications of the underlying reasons. Our findings suggest that predator avoidance is not causative for the observed pattern, probably because noctules are not as vulnerable to predation as slow flying bat species. On the other hand, when using the forest under moonlit conditions, noctules switched from flying above to flying underneath the canopy. Since noctules are not adapted to forage within dense forest, the reason might have been to avoid being spotted against the moonlit sky by predators ambushing from exposed tree branches. This may partially also explain the lower flight altitudes of $N$. noctula when foraging above open fields under moonlit conditions. Being an opportunistic forager [48], $N$. noctula seems to be able to shift its habitat use in response to moonlight in such a manner that it optimizes the exploitation of cyclic appearing insects while minimizing predation risk by adjusting their flight altitude and avoiding habitats with temporarily high predation risk.

Such a temporal plasticity in habitat use is supported by the finding the $N$. noctula not only spend more time above open fields, but also increased the relative amount of foraging behaviour above open fields during high moonlight intensities. We thus speculate that prey availability above open fields increases under moonlit conditions, turning open fields regularly into valuable foraging habitats for open-space foraging bats, and compensating for potentially increased predation pressure, at least for fast-flying bats like $N$. noctula. Unfortunately, literature on the effect of moonlight on insect abundances is contradictory. Reduced insect activity under moonlit conditions was reported in the early literature and yet later contradicted by some authors [73, 74], but other studies support the idea of moonlight avoidance by insects [41]. Some authors on the other hand suggest that emergence of insects is synchronized by the moon phase, with the timing of emergence being species-specific but most often associated with near full moon $[39,40]$. However, most studies on insect abundance so far used light-traps, a method that likely is biased during high moonlight intensities. Yela and Holyoak [75] showed that light-traps were less efficient for catching noctuid moths in forests during high moonlight intensities, while catches from bait traps were not influenced by moonlight. Using light-traps, [44] caught more
Lepidoptera under dark conditions and more Hemiptera under bright conditions. When investigating the diet of Myotis sodalis, they found a higher portion of Diptera and aquatic insects, and a lower portion of Lepidoptera with increasing moonlight. It remains unclear whether this shift in the diet could be attributed to shifting insect availability or to a shift in habitat selection by bats. Contrary to that, a study by [43] showed that especially open-habitat associated moths as well as dipteran species may be most active during moonlit nights. Bidlingmeyer [45] found that abundance of different mosquito species increased with moonlight when sampling with funnel traps on roads near a beach. This indicates that mosquitoes may synchronize hatching close to full moon and then distribute over the landscape. Overall, evidence is accumulating that many insect taxa synchronize hatching to the moonphase, yet without a consistent pattern for the exact time. This species-specific timing must thus result in different insect densities at the respective habitats of the insects, leading to temporal heterogeneity in habitat suitability for insectivorous predators. Especially light tolerant species such as $N$. noctula and other open space foraging bats $[38,76]$ may be able to exploit such insect rich open habitats despite intense moonlight. Further, a study by Eklöf et al. [77] showed that open space foraging bats use vision when hunting for moths in cluttered habitats, a fact they may have enhanced the foraging success of $N$. noctula when hunting at the edges of open fields during high moonlight intensities.

Yet, we must acknowledge that due to ethical and technical constraints, our study period was limited to the post breeding season. It might thus be that the observed responses towards moonlight levels may change throughout the season, e.g. when female bats are raising young and may thus be more risk sensitive towards potential predation.

\section{Conclusions}

This study confirms that predators such as insectivorous bats can be highly flexible in their use of space, probably in order to increase foraging efficiency by exploiting temporarily occurring prey accumulations. The shift of $N$. noctula from forested to open fields during high moonlight intensities argues against the notion that bats generally exhibit lunar phobia as a predator avoidance strategy and thus hide during moonlit nights. We speculate that some bat species actively chose open fields under moonlit conditions to exploit insects that are lured out of the vegetation when moonlight intensities are high. Yet, predator avoidance behaviour may explain decreases in bat activity in temporarily risky spaces, such as the space above the canopy of forested areas. Irrespective of the underlying reasons, the observed change in use of space highlights that habitat suitability is not static for bats and other nocturnal animals but may shift periodically in response to the lunar phase. 


\section{Additional files}

Additional file 1: Habitat types within the study area. The location of the artificial roosts is indicated by the white star. (PNG 3728 kb)

Additional file 2: Flight altitude for all recorded tracks. Each dot represents one GPS location, whereas colour depicts whether the observed movement behaviour was associated with foraging. Green ribbons depict the underlying canopy height in forested areas. Background colours depict the different habitat types; blue $=$ water /swamp, red = urban, light-green = open fields, dark-green = forests and scrub / successional growth. The colour of the horizontal bar on top of each trip depicts the moonlight intensity; black = low, yellow = high (PDF 2338 kb)

Additional file 3: Workflow to create the canopy height model by using the lastool software. (TXT 2 kb)

\section{Abbreviations}

chm: canopy height model; GPS: Global positioning system; LiDAR: Light detection and ranging

\section{Acknowledgements}

We thank Oliver Lindecke for discussions and Stephanie Kramer-Schadt for statistical advice.

\section{Funding}

MR was funded by the Deutsche Forschungsgemeinschaft (DFG-GRK 2118/1 - BioMove). The publication of this article was funded by the Deutsche Forschungsgemeinschaft (DFG-GRK 2118/1 - BioMove) and the Open Access Fund of the Leibniz Association. The funding agencies had no influence on the content of this study.

\section{Availability of data and materials}

GPS data are stored at the movebank data repository (Study ID 297041945 at https: \\movebank.org)

\section{Authors' contributions}

$C C V, T$, and UH conceived the study. TT, UH, and FK collected the data. MR analysed the data. MR and CCV wrote the manuscript. All authors read, commented on, and approved the manuscript.

\section{Ethics approval and consent to participate}

Not applicable.

\section{Consent for publication}

Not applicable.

\section{Competing interests}

The authors declare that they have no competing interests.

\section{Publisher's Note}

Springer Nature remains neutral with regard to jurisdictional claims in published maps and institutional affiliations.

\section{Author details}

'Leibniz Institute for Zoo and Wildlife Research, Alfred-Kowalke-Str. 17, 10315 Berlin, Germany. ${ }^{2}$ Institut für Biologie, Freie Universität Berlin, Takustr. 6, 14195 Berlin, Germany. ${ }^{3}$ Büro für faunistisch-ökologische Fachgutachten, Goldsternweg 34, 12524 Berlin, Germany. ${ }^{4}$ Natura Büro für zoologische und botanische Fachgutachten, Hans-Sachs-Str. 48, 15732 Schulzendorf, Germany.

\section{Received: 26 March 2018 Accepted: 3 July 2018}

Published online: 02 August 2018

\section{References}

1. Kotliar NB, Wiens JA. Multiple scales of patchiness and patch structure: a hierarchical framework for the study of heterogeneity. Oikos. 1990;59:253.

2. Kolasa J, Rollo CD. Introduction: the heterogeneity of heterogeneity: a glossary. In: Kolasa J, Pickett STA, editors. Ecol Heterog. New York: Springer; 1991. p. 1-23.
3. Wiens JA. Central concepts and issues of landscape ecology. In: Gutzwiller KJ, editor. Appl Landsc Ecol biol Conserv. New York: Springer New York; 2002. p. 3-21.

4. Petit DR. Weather-dependent use of habitat patches by wintering woodland birds. J F Ornithol. 1989;60:241-7.

5. Béchet A, Girouc J-F, Gauthier G. The effects of disturbance on behaviour, habitat use and energy of spring staging snow geese. J Appl Ecol. 2004;41:689-700.

6. Bailey $\mathrm{H}$, Secor DH. Coastal evacuations by fish during extreme weather events. Sci Rep. 2016;6:30280.

7. Sheppard JK, Jones RE, Marsh H, Lawler IR. Effects of tidal and diel cycles on dugong habitat use. J Wildl Manag. 2009;73:45-59.

8. Coppes J, Burghardt F, Hagen R, Suchant R, Braunisch V. Human recreation affects spatio-temporal habitat use patterns in red deer (Cervus elaphus). PLoS One. 2017:12:1-19.

9. Rehnus M, Marconi L, Hacklànder K, Filli F. Seasonal changes in habitat use and feeding strategy of the mountain hare (Lepus timidus) in the central alps. Hystrix. 2013;24:161-5.

10. Pyke GH, Pulliam HR, Charnov EL. Optimal foraging: a selective review of theory and tests. Q Rev Biol. 1977;52:137-54.

11. Cresswell WJ, Harris S. The effects of weather conditions on the movements and activity of badgers (Meles meles) in a suburban environment. J Zool. 1988;216:187-94.

12. Griffin PC, Griffin SC, Waroquiers C, Mills LS. Mortality by moonlight: predation risk and the snowshoe hare. Behav Ecol. 2005;16:938-44.

13. Brown JS, Kotler BP, Smith RJ, Wirtz WO. The effects of owl predation on the foraging behavior of heteromyid rodents. Oecologia. 1988;76:408-15.

14. Kotler BP, Brown JS, Hasson O. Factors affecting gerbil foraging behavior and rates of owl predation. Ecology. 1991;72:2249-60.

15. Bouskila A. Interactions between predation risk and competition: a field study of kangaroo rats and snakes. Ecology. 1995;76:165-78.

16. Mougeot F, Bretagnolle V. Predation risk and moonlight avoidance in nocturnal seabirds. J Avian Biol. 2000;31:376-86.

17. Van Orsdol KG. Foraging behaviour and hunting success of lions in queen Elizabeth National Park, Uganda. Afr J Ecol. 1984;22:79-99.

18. Funston PJ, Mills MGL, Biggs HC. Factors affecting the hunting success of male and female lions in the Kruger National Park. J Zool. 2001;253:419-31.

19. Rockhill AP, DePerno CSC, Powell RA, DePerno CSC, Hair J. The effect of illumination and time of day on movements of bobcats (Lynx rufus). PLoS One. 2013:8:e69213.

20. Palmer MS, Fieberg J, Swanson A, Kosmala M, Packer C. A "dynamic" landscape of fear: prey responses to spatiotemporal variations in predation risk across the lunar cycle. Ecol Lett. 2017;20:1364-73.

21. Penteriani $V$, Kuparinen A, del Mar Delgado M, Palomares F, Lopez-Bao JV Fedriani JM, et al. Responses of a top and a meso predator and their prey to moon phases. Oecologia. 2013;173:753-66.

22. Di Bitetti MS, Paviolo A, De Angelo C. Density, habitat use and activity patterns of ocelots (Leopardus pardalis) in the Atlantic Forest of Misiones, Argentina. J Zool. 2006;270:153-63.

23. Prugh LR, Golden CD. Does moonlight increase predation risk? Metaanalysis reveals divergent responses of nocturnal mammals to lunar cycles. $J$ Anim Ecol. 2014;83:504-14

24. Saldaña-Vázquez RA, Munguía-Rosas MA. Lunar phobia in bats and its ecological correlates: a meta-analysis. Mamm Biol. 2013;78:216-9.

25. Lang AB, Kalko EKV, Römer $H$, Bockholdt C, Dechmann DKN. Activity levels of bats and katydids in relation to the lunar cycle. Oecologia. 2006;146:659-66.

26. Börk KS. Lunar phobia in the greater fishing bat Noctilio leporinus (Chiroptera: Noctilionidae). Rev Biol Trop. 2006:54:1117-23.

27. Appel G, Lopez-Baucells A, Magnusson WE, Bobrowiec PED. Aerial insectivorous bat activity in relation to moonlight intensity. Mamm Biol. 2017:85:37-46

28. Leonard ML, Fenton MB. Habitat use by spotted bats (Euderma maculatum, Chiroptera: Vespertilionidae): roosting and foraging behaviour. Can J Zool. 1983;61:1487-91.

29. Negraeff OE, Brigham RM. The influence of moonlight on the activity of little brown bats (Myotis lucifugus). Zeitschrift für Säugetierkd. 1995;60:330-6.

30. Gaisler J, Zukal J, Rehak Z, Homolka M. Habitat preference and flight activity of bats in a city. J Zool. 1998;244:439-45.

31. Karlsson B-L, Eklöf J, Rydell J. No lunar phobia in swarming insectivorous bats (family Vespertilionidae). J Zool. 2006;256:473-7. 
32. Hecker KR, Brigham RM. Does moonlight change vertical stratification of activity by forest-dwelling insectivorous bats? J Mammal. 1999;80:1196-201.

33. O'Shea TJ, Cryan PM, Hayman DTS, Plowright RK, Streicker DG. Multiple mortality events in bats: a global review. Mamm Rev. 2016;46:175-90.

34. Lesiński G, Gryz J, Kowalski M. Bat predation by tawny owls Strix aluco in differently human-transformed habitats. Ital J Zool. 2009:76:415-21.

35. Rosina W, Shokhrin VP. Bats in the diet of owls from the Russian far east, southern Sikhote Alin. Hystrix. 2011;22:205-13.

36. Lima SL, O'Keefe JM. Do predators influence the behaviour of bats? Biol Rev. 2013;88:626-44

37. Norberg UM, Rayner JMV. Ecological morphology and flight in bats (Mammalia, Chiroptera) - wing adaptations, flight performance, foraging strategy and echolocation. Philos Trans R Soc London. 1987;316:337-419.

38. Rowse EG, Lewanzik D, Stone EL, Harris S, Jones G. Dark matters: the effects of artificial lighting on bats. In: Bats in the anthropocene: conservation of bats in a changing world. Cham: Springer International Publishing; 2016. p. 187-213.

39. Danthanarayana W. Lunar periodicity of insect flight and migration. In: Danthanarayana W, editor. Insect flight: dispersal and migration. Berlin, Heidelberg: Springer; 1986. p. 88-119.

40. Nowinszky L, Petranyi G, Puskas J. The relationship between lunar phases and the emergence of the adult brood of insects. Appl Ecol Environ Res. 2010;8:51-62.

41. Anthony ELP, Stack MH, Kunz TH. Night roosting and the nocturnal time budget of the little brown bat, Myotis lucifugus: effects of reproductive status, prey density, and environmental conditions. Oecologia. 1981;51:151-6.

42. Bhagawati R, Bhagawati K, Choudahary VK, Rajkhowa DJ, Bhagawati G. Lunar cycle based cropping calendar: indigenous approach of biological insect pest management. Res J Agric For Sci. 2015;3:1-6.

43. Nowinszky L, Kiss O, Szentkirályi F, Puskás J, Ladányi M. Influence of illumination and polarized moonlight on light-trap catch of caddisflies (Trichoptera). Res J Biol. 2012;2:79-90.

44. Brack V Jr, Laval RK. Food habits of the Indiana bat Myotis sodalis in Missouri. J Mammal. 1985;66:308-15.

45. Bidlingmayer WL. The effect of moonlight on the flight activity of mosquitoes. Ecology. 1964:45:87.

46. Schnitzler HU, Moss CF, Denzinger A. From spatial orientation to food acquisition in echolocating bats. Trends Ecol Evol. 2003;18:386-94.

47. Gloor S, Stutz HB, Ziswiler V. Nutritional habits of the noctule bat Nyctalus noctula (Shreber, 1774) in Switzerland. Myotis. 1995;32-33:231-42.

48. Vaughan N. The diets of British bats (Chiroptera). Mamm Rev. 1997;27:77-94.

49. Cvikel N, Levin E, Hurme E, Borissov I, Boonman A, Amichai E, et al. Onboard recordings reveal no jamming avoidance in wild bats. Proc R Soc BBiological Sci. 2015;282:20142274.

50. Roeleke M, Blohm T, Kramer-Schadt S, Yovel Y, Voigt CC. Habitat use of bats in relation to wind turbines revealed by GPS tracking. Sci Rep. 2016;6:28961.

51. Land Brandenburg. Flächendeckende Biotop- und Landnutzungskartierung im Land Brandenburg (BTLN) - CIR-Biotoptypen 2009. Data licence dl-de/ by-2-0, www.mugv.brandenburg.de/lua/gis/btln_cir_fl.zip www.mugv. brandenburg.de/lua/gis/btln_cir_li.zip (accessed 20042015). 2013;

52. Isenburg M. Rasterizing perfect canopy height models from LiDAR. 2014 Available from: https://rapidlasso.com/2014/11/04/rasterizing-perfectcanopy-height-models-from-lidar/

53. Michelot $T$, Langrock R, Patterson TA. moveHMM: an R package for the statistical modelling of animal movement data using hidden Markov models. Methods Ecol Evol. 2016;7:1308-15.

54. Manly B, McDonald L, Thomas D, McDonald T, Erickson W. Resource selection by animals: statistical analysis and design for field studies. Dordrecht: Kluwer Academics; 2002

55. Calenge $\mathrm{C}$. The package "adehabitat" for the R software: a tool for the analysis of space and habitat use by animals. Ecol Model. 2006;197:516-9.

56. Martin J, Calenge CCC, Quenette P-Y, Allainé D. Importance of movement constraints in habitat selection studies. Ecol Model. 2008;213:257-62.

57. Fox J. Effect displays in R for generalised linear models. J Stat Softw. 2003;8:1-27.

58. Hallmann CA, Sorg M, Jongejans E, Siepel H, Hofland N, Schwan H, et al. More than 75 percent decline over 27 years in total flying insect biomass in protected areas. PLoS One. 2017;12:e0185809.

59. Heim O, Lorenz L, Kramer-Schadt S, Jung K, Voigt CC, Eccard JA. Landscape and scale-dependent spatial niches of bats foraging above intensively used arable fields. Ecol Process. 2017;6:24.

60. Racey PA. The reproductive cycle in male noctule bats, Nyctalus noctula. J Reprod Fertil. 1974;41:169-82
61. Blohm T. Ansiedlungsverhalten, Quartier- und Raumnutzung des Großen Abendseglers (Nyctalus noctula, Schreber 1774) in der Uckermark. Nyctalus. 2003;9:123-57

62. Froidevaux JSP, Zellweger F, Bollmann K, Jones G, Obrist MK. From field surveys to LiDAR: shining a light on how bats respond to forest structure. Remote Sens Environ. 2016;175:242-50.

63. Kronwitter F. Population structure, habitat use and activity patterns of the noctule bat, Nyctalus noctula Schreb., 1774 (Chiroptera: Vespertilionidae) revealed by radiotracking. Myotis. 1988;26:23-85.

64. Rydell J, Petersons G. The diet of the noctule bat Nyctalus noctula in Latvia. Zeitschrift für Säugetierkd. 1998:63:79-83.

65. Müller J, Brandl R, Buchner J, Pretzsch H, Seifert S, Stratz C, et al. From ground to above canopy - bat activity in mature forests is driven by vegetation density and height. For Ecol Manag. 2013;306:179-84.

66. Redpath SM. Habitat fragmentation and the individual: tawny owls Strix aluco in woodland patches. J Anim Ecol. 1995;64:652.

67. Speakman JR, Rydell J, Webb PI, Hayes JP, Hays GC, Hulbert IAR, et al. Activity patterns of insectivorous bats and birds in northern Scandinavia $\left(69^{\circ} \mathrm{N}\right)$, during continuous midsummer daylight. Oikos. 2000;88:75-86.

68. Voigt CC, Lewanzik D. Trapped in the darkness of the night: thermal and energetic constraints of daylight flight in bats. Proc R Soc London B Biol Sci. 2011;278:2311

69. Speakman JR, Webb PI. Taxonomy, status and distribution of the Azorean bat (Nyctalus azoreum). J Zool. 1993;231:27-38.

70. Garcia AM, Cervera F, Rodriguez A. Bat predation by long-eared owls in mediterranean and temperate regions of southern Europe. J Raptor Res. 2005;39:445-53.

71. Charter M, Izhaki I, Leshem Y, Roulin A. Diet and breeding success of longeared owls in a semi-arid environment. J Arid Environ. 2012;85:142-4.

72. Speakman JR. The impact of predation by birds on bat populations in the British Isles. Mamm Rev. 1991:21:123-42.

73. Williams CB, Singh BP. Effect of moonlight on insect activity. Nature. 1951;167:853.

74. Williams CB, Singh BP, EL ZS. An investigation into the possible effects of moonlight on the activity of insects in the field. Proc R Entomol Soc London Ser A, Gen Entomol. 1956;31:135-44.

75. Yela JL, Holyoak M. Effects of moonlight and meteorological factors on light and bait trap catches of noctuid moths (Lepidoptera: Noctuidae). Environ Entomol. 1997;26:1283-90.

76. Meineke T. Phänologie und Verhalten flugaktiver Großer Abendsegler Nyctalus noctula ( Schreber, 1774 ) im südlichen Niedersachsen in den Jahren 2000 bis 2014. Säugetierkundliche Informationen. 2015;9:403-28

77. Eklöf J, Svensson AM, Rydell J. Northern bats, Eptesicus nilssonii, use vision but not flutter-detection when searching for prey in clutter. Oikos. 2002:99:347-51.

\section{Ready to submit your research? Choose BMC and benefit from:}

- fast, convenient online submission

- thorough peer review by experienced researchers in your field

- rapid publication on acceptance

- support for research data, including large and complex data types

- gold Open Access which fosters wider collaboration and increased citations

- maximum visibility for your research: over $100 \mathrm{M}$ website views per year

At BMC, research is always in progress.

Learn more biomedcentral.com/submissions 